\title{
EXTRAFISCALIDADE NAS PARCERIAS PÚBLICO-PRIVADAS: MECANISMO ALTERNATIVO DE VIABILIDADE
}

\section{EXTRAFISCALITY IN PUBLIC-PRIVATE PARTNERSHIPS: ALTERNATIVE MECHANISM OF VIABILIT}

\begin{abstract}
Welington Oliveira de Souza Costa
Mestrando em Direitos Humanos pela UFMS. Especialista em Gestão Pública na Administração Pública pela UFMS. Especialista em Direito Processual Civil com ênfase em Responsabilidade Civil pela Escola de Direito de Campo Grande - EDCG. Especialista em Educação em Direitos Humanos pela UFMS. Assessor Jurídico no Ministério Público do Estado de Mato Grosso do Sul. Tesoureiro da Federação Nacional dos Pós-Graduandos em Direito - FEPODI. Membro da Associação dos Pós-Graduandos da UFMS, na qualidade de Representante Jurídico.
\end{abstract}

Antonio Conceição Paranhos Filho

Professor Associado IV da Universidade Federal de Mato Grosso do Sul - UFMS. Graduado em Geologia pela Universidade Federal do Paraná. Mestrado e Doutorado em Geologia Ambiental pela UFPR. Bolsista CAPES de Doutorado Sanduíche na Universidade de Siena (Itália). Estágio de PósDoutorado no Instituto de Geociências da USP (2011 - bolsista PDS-CNPq), onde também obteve sua Livre Docência em 2015. Possui experiência em Geotecnologias aplicadas às Geociências, à Saúde e ao Meio Ambiente, com ênfase em Geologia Ambiental.

Daniele dos Santos Nogueira Justino Pós-graduanda em Direito Processual Civil pela Universidade Cândido Mendes - UCAM. Especialista em Gestão Pública pela Universidade Federal de Mato Grosso do Sul - UFMS. Advogada na área de Direito Cível, Bancário, Trabalhista e Consumerista.

Renan Lemos Livramento Mestrando em Administração - Estado, Organização e Sociedade pela Universidade Federal Fluminense - UFF. Especialista em Marketing pelo Instituto Brasileiro de Mercado de Capitais IBMEC. Bolsista CAPES pela Universidade Federal Fluminense - UFF. Graduado em Administração pela Universidade Federal do Rio de Janeiro - UFRJ.

Submissão em 29/04/2017

Aprovação em 14/06/2017

DOI: http://dx.doi.org/10.21671/rdufms.v3i1.3551 
Resumo: 0 presente artigo objetiva apontar as características das Parcerias Público-Privadas e demonstrar a necessidade de sua maior utilização como instrumento de viabilidade, implementação e excelência no serviço público. Para tanto, apontam-se séries de experiências desta modalidade, exitosas no país. Outrossim, em razão de sua ainda imatura exploração, a pesquisa aponta a importância do incentivo tributário para torná-las mais atrativas ao setor privado, aqui tratado no âmbito da extrafiscalidade por meio da isenção fiscal, inclusive com a análise de normatização já existente para este fim. Há, igualmente, breve análise de casos jurisprudenciais em que se analisa a viabilidade desta modalidade de concessão. A pesquisa, desenvolvida a partir do método indutivo e dedutivo, é bibliográfica e documental e, em termos de considerações finais, aponta a necessidade da maior utilização destas parcerias firmadas entre o setor público e o privado, justamente como forma de desenvolvimento do país em termos sociais e econômicos.

Palavras-chave: Parcerias Púbico-Privadas; Extrafiscalidade nas Parcerias Público-Privadas; Mecanismo alternativo de incentivo no serviço público e privado.

\begin{abstract}
This article aims to show the characteristics of the Public-Private Partnerships and to demonstrate the need for their increased use as a viability instrument, implementation and excellence in public service. For that, are shown a series of successful experiences of the concession in the country. Beside that, due to their still immature exploration, the research shows the importance of tax incentives to make them more attractive to the private sector, here treated under the extrafiscality using the isention, including the analysis of the law already created for that purpose. There are also brief analysis of jurisprudential cases witch analyzes the viability of the concession mode. The research, developed by the inductive and deductive method, is bibliographic and documental and, in terms of final considerations, indicates the need for greater use of these partnerships signed between the public and private sectors, just as a way of social and economic development of the country.
\end{abstract}

Keywords: Public-Private Partnerships; Extrafiscality in Public-Private Partnerships; Alternative incentive mechanism in the public and private service.

SUMÁRIO: 1. Introdução. 2. Características das Parcerias Público-Privadas.

3. Parcerias Público-Privadas na Gestão Pública do País. 4. Extrafiscalidade: Mecanismo Alternativo para Viabilidade. 5. Parcerias Público-Privadas: Consolidação do Princípio da Eficiência e Políticas Públicas. 6. Jurisprudência Pátria. Conclusão. Referências.

\title{
1. INTRODUÇÃO
}

Instituída pela Lei Federal no. 11.079/04 (BRASIL. Lei 11.079 de 30 de dezembro de 2004, artigo $1^{\circ}$ ), esta modalidade de concessão de serviço público denominada Parceria Público-Privada - PPP trata-se de parceria elaborada entre a Administração e o particular para a realização de serviço de natureza pública.

Tem a finalidade principal de proporcionar excelência na prestação do serviço concedido ao particular, o qual, no caso, poderá ser exercido por meio de pagamento do Poder Público e utilização da tarifa cobrada pelo serviço (concessão patrocinada) ou pagamento total por parte da Administração (concessão administrativa). 
A efetividade destas parcerias já se demonstra palpável em alguns Estados da Federação. Cita-se o exemplo do Programa Ensino Médio Inovador - Jovem do Futuro no Rio Grande do Sul, que propõe a reorganização da grade curricular das escolas a fim de torná-las mais dinâmicas e garantir o acesso ao ensino superior, além dos casos de exploração de obras de saneamento em estados como Espírito Santo, Pernambuco e Mato Grosso.

Entretanto, em razão da quantia mínima a ser investida na obra, são pouco visadas pelo setor privado, que nelas vislumbra mais riscos do que atrativos. Desta maneira, a alternativa viável para a modificação da problemática demonstra-se plausível na diferenciação da tributação, falando-se então na extrafiscalidade tributária, modalidade de estímulo utilizada como fomento, de acordo com o interesse público. Portanto, mormente no caso em estudo, por meio de isenções concedidas por lei, é possível criar mecanismo alternativo de incentivo fiscal que viabiliza a adesão às parcerias público-privadas, bem como a melhoria do serviço público.

A esse passo, inicialmente, a presente pesquisa apresenta as características das parcerias público-privadas para melhor entendimento sobre suas formas e meios de implementação. Em seguida, são demonstrados, de forma exemplificativa, casos destas concessões já implementadas no país e as vertentes em que atuam.

Por outro lado, em razão da problemática já apontada, como forma de viabilizar as parcerias público-privadas, ainda pouco utilizadas, a pesquisa apresenta a extrafiscalidade como mecanismo alternativo de fomento destas concessões, citando-se inclusive normativa já existente para esse fim. E por fim, a fim de aprofundar o assunto em termos práticos, são analisados, brevemente, casos judiciais julgados pelos Tribunais envolvendo as parcerias aqui tratadas e seus benefícios.

A pesquisa, desenvolvida por ambos os métodos, indutivo e dedutivo, bibliográfica e documental, conclui pela importância desta modalidade de concessão do serviço público em parceria com o privado e levanta a discussão de seu fomento por meio da extrafiscalidade como forma de desenvolver as esferas públicas e privadas e, consequentemente, a economia do país.

\section{CARACTERÍSTICAS DAS PARCERIAS PÚBLICO-PRIVADAS}

As parcerias público-privadas são concessões especiais de serviços públicos, instituídas pela Lei Federal no. 11.079/04 (BRASIL. Lei 11.079 de 30 de de-

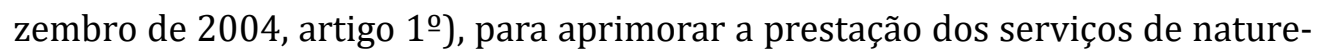
za pública por meio da sua concessão aos particulares interessados em fazê-lo. Segundo leciona Meirelles (2009, p. 405) "destina-se, ao que parece, a permitir 
a inserção do setor privado em serviços até agora pouco atrativos, como a construção e administração de presídios, hospitais, escolas e outros setores".

Para Di Pietro (2010, p. 306):

[...] é o contrato administrativo de concessão que tem por objeto: (a) a execução de serviço público, precedido ou não de obra pública, remunerada mediante tarifa paga pelo usuário e contraprestação pecuniária do parceiro público, ou (b) a prestação de serviço de que a Administração Pública seja usuária direta ou indireta, com o sem execução de obra e fornecimento e instalação de bens, mediante contraprestação do parceiro público.

José dos Santos Carvalho FIlho (2010, p. 460/461) aponta o sucesso da adoção das parcerias público-privadas em outros ordenamentos jurídicos, tais como Portugal, Espanha, Inglaterra e Irlanda e justifica seu êxito, principalmente no caso dos países ainda em desenvolvimento, na falta de recursos financeiros públicos e eficiência na gestão privada.

São tratadas como concessões especiais de serviços públicos em razão da existência da concessão ordinária, regida pela Lei nํ. 8.987/95, para diferenciálas. Também possuem particularidades, como o prazo de concessão do serviço (5 a 35 anos) e o valor necessário à realização da licitação para os particulares (mínimo de vinte milhões de reais), cabendo ao gestor público elaborar o projeto. E ainda, são divididas em dois tipos, sendo que a primeira, chamada concessão patrocinada, ocorre quando, apesar de ter sido concedido, o serviço público conta com recursos da Administração e da eventual tarifa cobrada. Já a concessão administrativa não contará com a verba proveniente da tarifa, mas tão somente aquela acordada com o Poder Público.

Em suma, ainda como explica José dos Santos Carvalho Filho (2010, p. 463), na concessão patrocinada há o recebimento de recursos de duas fontes, a primeira decorrente das tarifas dos usuários e a segunda da contraprestação do poder concedente. Na administrativa, há apenas o pagamento pelo concedente pois o serviço não comporta contraprestação tarifária.

Nesse sentido, as parcerias público-privadas são modalidades de concessão que possibilitam à Administração obter excelência na prestação de serviços de sua competência, por meio de contrato firmado com particulares, podendo receber recurso direto (Poder Público) e indireto (tarifa da prestação do serviço), ou pelas duas formas.

Este tipo de concessão, por ser estabelecida por lei federal, em consonância com o artigo 175 da Constituição Federal que, por sua vez, autoriza a realização do serviço 
público por meio de concessão, desde que haja licitação e prestação de contas, pode ser utilizada em âmbito Federal, Estadual, Municipal e pelo Distrito Federal, por leis promulgadas para esse fim, sendo que, para o primeiro ente aludido, a legislação faz menção específica da necessidade de estudo do caso e instituição de fundo para garantia das parcerias. Porém, por uma questão de simetria, o mesmo ocorre com os demais. Nas palavras de Carvalho Filho (2010, p. 469):

A Lei no. 11.079/2004 contempla, ainda, um capítulo com normas aplicáveis somente às parcerias federais. Para esse fim determina a instituição de um órgão gestor, com a participação de representantes dos Ministérios do Planejamento, da Casa Civil e da Fazenda, ao qual caberá o estudo prévio do mérito do projeto e da viabilidade da concessão da garantia financeira (art. 14). Prevê também a criação de um Fundo Garantidor de Parcerias - FGP, que será administrado, gerido e representado por instituição financeira controlada pela União (arts. 16 a 21).

Assim, as verbas para dispêndio com as contratações de parcerias público-privadas deverão existir e, a critério de estudo realizado, podem ser disponibilizadas caso a proposta seja aceita, por meio de processo licitatório.

As concessões especiais são, desta forma, opção vantajosa ao administrador que deseja obter eficiência na atuação pública, valendo-se da iniciativa privada como coautora na gestão e também beneficiária da prestação do serviço. Logo, em vista da crescente demanda pública aliada à premente necessidade de efetiva prestação, apresentam-se as parcerias público-privadas para a melhoria dos serviços e obtenção de excelência na gestão do ente que as aderir (CARVALHO FILHO, 2010, p. 468).

Por outro lado, ainda são pouco utilizadas e o motivo encontra-se no seu custo elevado que desvia o olhar do investidor privado, o qual, em tempos complexos de instabilidade financeira do país, não vê oportunidade de investimento sem que haja estímulo para tanto.

\section{PARCERIAS PÚBLICO-PRIVADAS NA GESTÃO PÚBLICA DO PAÍS}

As empresas especializadas habilitadas e contratadas após processo licitatório poderão exercer o múnus público com total êxito e prestatividade, muitas vezes melhor do que a própria Administração Pública faria naquele momento. Nesse sentido, as parcerias aqui estudadas buscam o auxílio privado em âmbito público por meio do gestor que, firmando os contratos, garante o bem-estar de seus administrados. 
José dos Santos Carvaho Filho (2010, p. 461) lembra que esta forma de prestação de serviço público tem ganhado espaço entre as discussões legislativas e, dentro da gestão pública, demonstra-se como meio viável à boa execução de serviços essenciais, tais como educação, construção de presídios e infraestrutura nas vias de transportes, como aponta Meirelles (2009, p. 405).

Sob este enfoque, podem-se citar alguns estados da federação que já adotam esta forma na administração pública para execução de diversos serviços.

O Espírito Santo possui lei dispositiva sobre as parcerias público-privadas e legislação acerca do fundo de gestão (ESPÍRITO SANTO. Lei Complementar no 492 de 10 de agosto de 2009 e Portaria no. 029-S/10), atribuindo, ainda, como ponto principal para atuação, a área de mobilidade urbana (rodovias, ferrovias, dentre outros) e saneamento básico. Da mesma forma, a Bahia (BAHIA. Lei no 9.290 de 27 de dezembro de 2004, artigo 1ํ), Minas Gerais (MINAS GERAIS. Decreto n‥ 43.702 de 16 de dezembro 2003, artigo 1으, e Lei no. 14.869 de 16 de dezembro de 2003, artigo 1ํ) e Pernambuco (PERNAMBUCO. Lei oㅜ. 12.765 de 2005, artigo $1^{\mathrm{o}}$ ), que inclusive possui legis sobre os projetos prioritários para as concessões especiais, como construção de rodovias (Projeto no. 1557), criação de Sistemas de Abastecimento de Água e tratamento de Esgoto (Projeto no. 1558), dentre outros.

Menciona-se também o estado do Rio Grande do Sul (RIO GRANDE DO SUL. Lei n⿳o. 12.234 de 13 de janeiro de 2005, artigo $1^{\circ}$ ), cabendo destacar, outrossim, o Estado de Mato Grosso que, recentemente, por meio da Lei no. 9.641/11 (MATO GROSSO. Lei 9.641 de 17 de novembro de 2011, artigo $1^{\circ}$ ), instituiu as parcerias público-privadas, com prioridade voltada para as áreas de segurança pública, educação, assistência social, transportes, saneamento, segurança, ciência e tecnologia e agronegócios.

A descentralização do serviço em muitos casos garante a efetividade e possibilita ao Estado investir em outras áreas que não estejam sob concessão. A transferência da titularidade tem também o propósito de beneficiar a população, tal como vem ocorrendo em muitos estados da federação brasileira. Por outro lado, não basta apenas que os estados tenham inclinação à disposição do serviço ao particular, mas que este lhe seja atrativo a ponto de pretender realizar o investimento.

Isto porque, em vista do alto custo da obra, aliada às incertezas de seu êxito e efetiva participação do Poder Público que invariavelmente está sempre em posição mais vantajosa no contrato de concessão, é necessário criar incentivo ao investimento e maior difusão das parcerias público-privadas, o que enseja a implementação fiscal, aqui trabalhada na forma da extrafiscalidade. 


\section{EXTRAFISCALIDADE: MECANISMO ALTERNATIVO PARA VIABILIDADE}

Extrafiscalidade pode ser conceituada como a forma de obter uma conduta sem a necessidade de arrecadação fiscal. Possui aporte constitucional e está relacionada ao interesse do Estado, o que acarreta em sua intervenção. Nas palavras de Gouvêa (2006), é meio para obtenção de receitas em outras formas fora da tributação, a exemplo das isenções, benefícios, progressividades, dentre outros.

É dizer que se tratam de formas fiscais alternativas para obter viabilidade em fazer ou deixar de fazer algo em benefício do Estado. Em sentido amplo, serve como estímulo ao pretendido pelo Poder Público de acordo com seu interesse. No caso em estudo, como forma de fomento das concessões especiais ao setor privado, adotar-se-á a modalidade de isenção tributária para a implementação da extrafiscalidade.

Nas palavras de Carrazza (2012, p. 980), isenção é a dispensa legal do pagamento do tributo. Brito (2010, p. 244) nos lembra que esta só ocorre por lei e, a despeito de certas controvérsias existentes quanto à incidência ou não do tributo no caso da isenção, certo que, para fins de extrafiscalidade desta pesquisa, basta que adotemos o entendimento de que não há tributação em razão de um interesse estatal maior.

Sabbag (2009, p. 822), tratando da isenção dentro da extrafiscalidade, quando cita Leandro V. Paulsen, aponta que o interesse público guiará a lei isentiva para a obtenção da extrafiscalidade no plano mediato e da justiça fiscal.

E ainda, Carrazza (2012, p. 1.008) recorda que a isenção se divide em condicionais, incondicionais, temporárias e indeterminadas. No caso da condicional, também chamada bilateral e onerosa há uma contraprestação do beneficiário, que decidirá se, uma vez enquadrado na legislação, a ela aderirá.

Portanto, traçadas as linhas conceituais, o propósito da extrafiscalidade como forma de incentivo à adesão do setor privado nas parcerias público-privadas, in casu implementada por meio de isenção tributária, materializa-se em estímulos fiscais iniciais e temporários quando da execução da obra, em diálogo direto do Poder Público com o Privado.

É o caso da Lei Federal no. 12.766/2012 (BRASIL. Lei 12.766 de 27 de dezembro de 2012), que alterou o parágrafo segundo do artigo sexto da lei das Parcerias Público-Privadas, a fim de possibilitar os aportes de recursos para aquisição de bens, excluindo tal valor da base de cálculo da Contribuição Social para o Programa de Integração Social e o Programa de Formação do Patrimônio do Servidor Público - PIS/Pasep, bem como da Contribuição Social para o Financiamento da Seguridade Social - COFINS. 
Conforme ensina Harada (2013, p. 324), as contribuições sociais são espécies tributárias vinculadas à atuação indireta do Estado. Destarte, a depender da quantia da obra, a tributação muitas das vezes acaba sendo pesada ao investidor. A medida em questão em boa hora veio justamente estimular à adesão desta modalidade de concessão especial, melhorando a prestação de determinados serviços públicos com vistas ao bem-estar social. 0 interesse público está bastante claro, o que justifica a isenção.

Gasparini (2005, p.382) ressalta que esta modalidade de concessão especial pretende o aproveitamento da atuação privada, que está livre de certas peias burocráticas para efetivar o serviço público e garantir o bem-estar da população, finalidade última da gestão pública.

Lima, Paula e de Paula (2007) esposam o mesmo raciocínio:

Em linhas gerais as PPPs apresentam-se como alternativa positiva à atual situação econômico-financeira e social do Brasil - situação esta cultivada a longas décadas de déficit público e a elevado custo social. Assim, representam importante instrumento para viabilizar investimentos em infra-estrutura e serviços de utilidade pública, utilizando-se de novo padrão de financiamento. Contudo, para um crescimento sustentável em longo prazo, devem ser observados os parâmetros dispostos na Lei de Responsabilidade Fiscal, como forma de garantir a transparência na utilização de recursos públicos no decorrer de variadas gestões. De fato, as repercussões políticas e econômicas só poderão ser notadas pela sociedade brasileira no decorrer da efetiva implementação de contratações na modalidade de Parceria Público Privada.

Desta forma, a utilização da extrafiscalidade para atrair investimento privado por meio de contrato de parcerias público-privadas é medida alternativa à solução de duas problemáticas prementes: o fomento e adesão desta modalidade de concessão especial de serviço público e a melhoria da prestação do serviço licitado, almejando sempre o bem-estar dos administrados.

\section{PARCERIAS PÚBLICO-PRIVADAS: CONSOLIDAÇÃO DO PRINCÍPIO DA EFICIÊNCIA E POLÍTICAS PÚBLICAS}

0 princípio da eficiência vigente no caput do artigo 37 da Constituição Federal de 1988 (CONSTITUIÇÃO FEDERAL. Artigo 37) foi inserido com a edição da Emenda Constitucional no 19 de 1998 (CONSTITUIÇÃo FEDERAL. Emenda Constitucional n. 19 de 4 de junho de 1998), sendo até então apenas um princípio implícito, isto é, não estava expresso formalmente. Trata-se de um princípio contemporâneo, com previsão expressa também na redação da 
Lei n. 9.784/99 (BRASIL. Lei 9.784 de 29 de janeiro de 1999), que regula o processo administrativo no âmbito da Administração Pública Federal e veicula a obrigatoriedade de que os agentes públicos busquem em seus desempenhos os melhores resultados possíveis e a coletividade tenha suas demandas atendidas com presteza, atendimento qualitativo e satisfatório, viabilizando a eficiente atuação de seus agentes.

Quanto aos princípios institucionais dos serviços públicos, José dos Santos Carvalho Filho (2010, p.356) elucida que:

Princípio da Eficiência: Deve o Estado prestar seus serviços com a maior eficiência possível. Conexo com o princípio da continuidade, a eficiência reclama que o Poder Público se atualize como os novos processos tecnológicos, de modo que a execução seja mais proveitosa com menos dispêndio.

Logo, é cabível afirmar que a eficiência consistirá na base da contratação das parcerias público-privadas, pois, por meio dela, são almejadas políticas públicas mais adequadas para alcançar efetividade das ações e dos programas governamentais.

Ao se adentrar na seara de uma parceria entre o ente público e o setor privado, temos um universo de possibilidades. Entre direitos e deveres instituídos às partes com a redação da Lei 11.079 de 2004 (BRASIL. Lei 11.079 de 30 de dezembro de 2004) observa-se o princípio da eficiência apontando para a racionalidade do funcionamento da Administração Pública, enaltecendo dessa forma a finalidade de tal parceria.

O controle imprudente dos recursos do setor público, que fere o princípio da economicidade, também constitui lesão ao princípio da eficiência. Não é possível afirmar que a Administração Pública seja eficiente se também não forem eficientes os processos por ela geridos e os agentes que a compõem. Tal está associado também ao princípio da boa administração pública, pois visa à presteza na atuação e melhor gerenciamento de seus recursos.

Em referência às atuações típicas do Estado, os serviços públicos propriamente ditos, bem como aquelas próprias dos particulares, o que se discute nesta pesquisa é que em determinadas circunstâncias a parceria entre estas partes é bastante viável, visando a melhor realização possível da gestão dos interesses públicos, coroando a relação dentro da boa administração dos interesses públicos.

Logo, a distinção entre o público e o privado não exime que os atos praticados pela Administração Pública sejam dotados de qualidades intrínsecas de 
excelência, de modo a possibilitar o melhor atendimento possível das finalidades previstas em lei.

O princípio em tela associa-se também à definição de Administração Pública Gerencial, oriunda da reforma administrativa em vigor, a qual viabiliza um modelo de administração que privilegia a desburocratização e a descentralização administrativa, ou seja, uma visão que considera o Estado uma empresa e seus serviços destinados aos clientes, no caso, cidadãos, mas voltados também para a eficiência dessas atividades, tais quais na avaliação de seu desempenho bem como no controle de resultados.

Em uma sociedade capitalista o desafio imposto à gestão pública é exatamente o de criar continuamente instrumentos apropriados para garantir o equilíbrio mínimo entre os princípios opostos existentes na sociedade, de forma a fortalecer o bem-estar da coletividade, conservar e suscitar a liberdade e autonomia dos seus cidadãos, conforme os princípios que regem a Administração Pública.

Esta é a razão pela qual a própria lei no 11.079 de 2004 (BRASIL. Lei 11.079

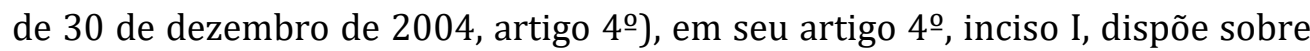
"a eficiência no cumprimento das missões de Estado e no emprego dos recursos da sociedade".

$\mathrm{Na}$ consolidação de tal princípio norteador, ao contratar-se parceria público-privada, a proposta da extrafiscalidade apresenta-se como possibilidade para inserir e fomentar políticas públicas, com o fim de atrair determinado setor econômico, ou até mesmo estimular certa atividade ou serviço, idealizando meios que garantem o bom funcionamento público em prol de incentivo ao setor privado.

A extrafiscalidade é uma medida que pode ser adotada pelo Estado, de maneira a viabilizar a garantia da efetividade dos direitos constitucionalmente delimitados por meio da incidência de tributos de maneira diferenciada. $\mathrm{E}$ constituindo tal ato uma política pública na atuação do poder público para a consecução da finalidade pública, é dever do Estado a adoção de um núcleo estratégico que formule e controle a implementação destas políticas, incrementando sua eficiência.

É válido afirmar dessa forma que a utilização dos meios extrafiscais de cobrança tributária são instrumentos de implementação de políticas públicas, ou seja, uma medida de utilização de efetividade para consagrar e atingir a sua finalidade pública.

Ressalta-se que no processo de implementação, acompanhamento, avaliação e controle das políticas públicas, é preciso incorrer na diferenciação de 
eficácia, eficiência e efetividade, na Gestão Pública, pois apesar de estarem interligados, possuem significados distintos. Segundo ensina Arretche (2001) a eficácia relaciona diretamente metas e objetivos, de forma a medir a sua consecução em sua plenitude. A eficiência relaciona a atividade empregada com os custos em questão, tais quais os financeiros, humanos e tempo. E finalmente a efetividade relaciona a atividade mencionada com seus efeitos na realidade a ser transformada, isto é, consequências.

Nas palavras de Berti (2009. p. 42):

[...] ao incidir sobre situações, fatos ou estados de fato, indicativas da existência de capacidade econômico-contributiva dos sujeitos passivos, os impostos viabilizam a efetivação de inúmeras políticas públicas voltadas à realização de objetivos sociais e econômicos nas mais diferentes áreas da atuação das pessoas físicas e jurídicas", promovendo ou reprimindo condutas, estimulando ou dificultando o desenvolvimento de mercados, ensejando ou inviabilizando atos e negócios jurídicos.

Assim, embora haja certa relutância na celebração das parcerias públicos-privadas, analisando-as sob a ótica de políticas públicas, que objetivem delinear um melhor modelo na administração à luz desta parceria, é válida a discussão da temática como forma de minimizar custos demasiado elevados para a sua atuação, propondo-se assim a extrafiscalidade como meio objetivo de operacionalizar a sua execução ao atingir a finalidade pública.

\section{JURISPRUDÊNCIA PÁTRIA}

As parcerias público-privadas, quando instituídas, são dotadas de previsão orçamentária e criação de fundo investidor, o que afasta a possibilidade de fraude ou inadimplência do ente contratante.

Outrossim, segundo discorrido, de acordo com a legislação aplicável, as concessões especiais serão utilizadas quando o valor da contratação não for inferior a $\mathrm{R} \$ 20.000 .000,00$ (vinte milhões de reais). Ademais, existe a possibilidade de, além da verba acordada, a empresa contratada valer-se da tarifa cobrada pelo serviço.

Nesta senda, com a aplicação da extrafiscalidade, o setor particular só tem a ganhar com o investimento no público, em especial pelo incentivo tributário posto à disposição dos empresários do Brasil, que poderá ocorrer nas mais variadas formas, diferentes do exemplo trazido pela lei no. 12.766/12 (BRASIL. Lei 12.766 de 27 de dezembro de 2012).

Não se olvida, da mesma forma, que esta é a finalidade da Lei no (BRASIL. Lei 8.666 de 1993) para que, por meio da participação da maior 
quantidade de concorrentes possível, encontre-se a melhor proposta na licitação em benefício ao ente público. 0 incentivo fiscal aqui discutido também atua nesse momento da contratação.

Cabe ressaltar que, tratando juridicamente do caso em testilha, os Tribunais já julgaram casos relativos às parcerias entre o setor público e privado, tratando a questão dentro dos limites impostos pelos princípios da proporcionalidade e razoabilidade. É o que se infere do julgado abaixo colacionado proveniente do Estado do Rio de Janeiro:

Agravo de instrumento interposto contra decisão interlocutória proferida nos autos da Medida Cautelar ajuizada pelo ente público municipal em face da concessionária vencedora da licitação. Contrato de concessão especial de Parceria Público-Privada firmado na modalidade administrativa. Inadimplemento do ente municipal sob a alegação de imperfeição na conclusão da obra. Questão eminentemente técnica, isto porque, se trata de uma obra grandiosa em que eventuais itens mal executados não comprometem inteiramente a operação do sistema sanitário e, portanto, não justificaria reter o pagamento, não se mostrando razoável que o Município prorrogue o início dos pagamentos por defeitos de execução que podem ser reparados ao longo da manutenção prevista no contrato. Recurso provido.

No caso acima relatado, inobstante a obra realizada tivesse algumas falhas técnicas, estas não obstaram a obrigatoriedade da realização de pagamento do valor contratado com a Administração. Outrossim, ainda traçando paralelo sobre o julgado em comento, a aplicação dos princípios da proporcionalidade e razoabilidade igualmente é lembrada da questão da extrafiscalidade, já que é justamente por meio desta ponderação pelo ente público a extrafiscalidade é implementada e viabilizada a utilização das parcerias público-privadas.

Não obstante, eis julgado relacionado ao caso tributário advindo do Tribunal de Justiça do Estado de São Paulo:

Ação direta de inconstitucionalidade. Lei no 3.789/2015 do Município de Mirassol, que altera dispositivos da Lei municipal n.ㅇ 3.097/2007, acerca de Programa de Parceria Público Privada, e autoriza o Poder Executivo a conceder desconto em tributos que especifica. Diploma de origem parlamentar. Vício de iniciativa não caracterizado, já que quanto à matéria financeiro-tributária a competência é concorrente. Precedentes. Ofensa reconhecida, contudo, aos princípios da separação de poderes e da reserva legal. Art. 5ํ, inciso II, e 163, § 6º da Constituição estadual. Causa de pedir aberta que permite o reconhecimento de tal sorte de contrariedade. Ação procedente. 
No caso acima, entretanto, ao conceder benefícios fiscais, houve inconstitucionalidade no tocante à forma de sua concessão, que acabou por ser delegada pelo chefe do Executivo. Por outro lado, a exemplificação apenas demonstra a inclinação crescente deste tipo de incentivo para maior difusão das parcerias público-privadas.

O fato é que, assim como nos lembra Gonzalez (2005), estas novas formas de investimento por parte do setor privado é avanço em matéria de contratação pública, possibilitado por meio de instrumentos eficazes de controle e fiscalização, inclusive judicial, na forma aqui exposta.

\section{CONCLUSÃO}

Por meio deste artigo, pretendeu-se demonstrar, inicialmente por meio conceitual, as vantagens das parcerias público-privadas e a necessidade de sua maior implementação no país. A esse passo, são citados exemplos exitosos de implementação e utilização destas concessões de serviço público em diversos Estados da Federação.

Entretanto, por questões de incentivo, são ainda pouco utilizadas, o que não se afigura plausível se considerarmos as grandes vantagens que aportam em seu bojo.

Nesse ponto, a extrafiscalidade, tratada na pesquisa como isenção tributária, traz a possibilidade de maior investimento do setor privado. Logo, as PPPs constituem-se mecanismos alternativos bastante vantajosos, com inúmeros benefícios ao Poder Público, ao particular contratado e principalmente aos administrados que fizerem uso do serviço.

Em vista das vantagens trazidas pelas parcerias público-privadas, é certo que sua efetiva utilização só tem a beneficiar o Poder Público e, consequentemente, a população beneficiária do serviço prestado, além do incentivo à iniciativa privada, o que demonstra a relevância da pesquisa também em termos de avanços sociais e econômicos. A participação privada garante a eficiência necessária dentro da Administração Pública, sendo a extrafiscalidade fundamental para o incentivo ao setor privado.

Ademais, os casos legislativos citados, aliados à jurisprudência colacionada, demonstram cabalmente o êxito na implementação extrafiscal nas concessões especiais como forma de fomentá-las, donde se espera maior empenho do gestor na inclusão das PPPs dentro das administrações do país. O controle judicial, inclusive, serve como vetor a ilegalidades e garante a consolidação dos princípios da administração pública, mormente a legalidade e a eficiência. 
A pesquisa, entretanto, ainda é muito escassa e pouco aprofundada, o que demonstra o estado atual da arte e convida a maior implementação das Parcerias Público-Privadas para que os casos práticos sejam referências tanto aos incentivos fiscais quanto ao efetivo desenvolvimento do país, em termos econômicos e sociais. Desta forma, em termos de comprovação dos fatos aqui investigados frente à problemática posta, inevitavelmente conclui-se que os benefícios adjuntos à esta modalidade de concessão de serviço são vantajosos e acessíveis, o que constitui alternativa viável frente às necessidades atuais do país.

\section{REFERÊNCIAS}

BAHIA. Lei no. 9.290 de 27 de dezembro de 2004. Institui o Programa de Parcerias Público-Privadas do Estado da Bahia - PPP Bahia e dá outras providências. In: Assembleia Legislativa do Estado da Bahia, BA, 27 dez. 2004. Disponível em: <http://www. legislabahia.ba.gov.br/index.php?pag=pesqavanc>. Acesso em 10 abril 2012.

BRASIL. Lei no 11.079 de 30 de dezembro de 2004. Institui normas gerais para licitação e contratação de parceria público-privada no âmbito da administração pública. In: Diário Oficial da República Federativa do Brasil, Brasília, DF, 30 dez. 2004.Disponível em: <http://www.planalto.gov.br/ccivil_03/_ato2004-2006/2004/lei/l11079.htm>. Acesso em 20 mai. 2016.

BRASIL. Lei no. 8.987 de 13 de fevereiro de 1995. Dispõe sobre o regime de concessão e permissão da prestação de serviços públicos previsto no art. 175 da Constituição Federal, e dá outras providências. In: Diário Oficial da República Federativa do Brasil, Brasília, DF, 13 fev. 1995. Disponível em: <http://www.planalto.gov.br/ccivil_03/_ato2004-2006/2004/ lei/l11079.htm>. Acesso em 20 mai. 2016.

BRASIL. Constituição Federal. Brasília: Senado Federal, 1988. Disponível em: <http:// www.planalto.gov.br/ccivil_03/constituicao/constituicaocompilado.htm>. Acesso em 25 mai. 2016.

BRASIL. Lei no .12 .766 de 27 de dezembro de 2012. Altera as Leis nos 11.079, de 30 de dezembro de 2004, que institui normas gerais para licitação e contratação de parceria público-privada no âmbito da administração pública, para dispor sobre o aporte de recursos em favor do parceiro privado, 10.637, de 30 de dezembro de 2002, 10.833, de 29 de dezembro de 2003, 12.058, de 13 de outubro de 2009, 9.430, de 27 de dezembro de 1996, 10.420, de 10 de abril de 2002, 10.925, de 23 de julho de 2004, 10.602, de 12 de dezembro de 2002, e 9.718, de 27 de novembro de 1998, e a Medida Provisória no 2.158-35, de 24 de agosto de 2001, e dá outras providências. In: Diário Oficial da República Federativa do Brasil, Brasília, DF, 28 dez. 2012. Disponível em: < http://www. planalto.gov.br/ccivil_03/_ato2011-2014/2012/lei/112766.htm>. Acesso em 08 abr. 2016.

BRASIL. Lei no. 8.666 de 21 de junho de 1993. Regulamenta o art. 37, inciso XXI, da Constituição Federal, institui normas para licitações e contratos da Administração Pública e dá outras providências. In: Diário Oficial da República Federativa do Brasil, Brasília, DF, 22 jun. 1993. Disponível em: <http://www.planalto.gov.br/ccivil_03/leis/L8666cons.htm>. Acesso em 08 jun. 2016. 
BRASIL. Ministério do Planejamento. Projetos de Parcerias Público-Privadas. Disponível em: <http://www.planejamento.gov.br/hotsites/ppp/conteudo/projetos/estaduais/estaduais. html>. Acesso em 20 de abr. 2012.

BRASIL. Emenda Constitucional no 19 de 04 de Junho de 1998. Modifica o regime e dispõe sobre princípios e normas da Administração Pública, servidores e agentes políticos, controle de despesas e finanças públicas e custeio de atividades a cargo do Distrito Federal, e dá outras providências. In: Diário Oficial da República Federativa do Brasil, Brasília, DF. Disponível em: <https://www.planalto.gov.br/ccivil_03/constituicao/ Emendas/Emc/emc19.htm>. Acesso em 14 Nov. 2016.

BRASIL. Lei no․ 9.784 de 29 de janeiro de 1999. Regula o processo administrativo no âmbito da Administração Pública Federal. In: Diário Oficial da República Federativa do Brasil, Brasília, DF, 29 jan. 1999. Disponível em: < http://www.planalto.gov.br/ccivil_03/ leis/L9784.htm>. Acesso em 08 jun. 2016.

BRASIL. Tribunal de Justiça do Estado de São Paulo. ADI no. 2176028-61.2015.8.26.0000 que julgou procedente a ação direta de inconstitucionalidade de lei Municipal. Relator: Arantes Theodoro. Julgamento em 18.05.2016. Disponível em: <https://esaj.tjsp.jus.br/cjsg/getArquivo. do?cdAcordao=9445053\&cdForo=0\&vlCaptcha=Cjqym $>$. Acesso em 09 jun. 2016.

BRASIL. Tribunal de Justiça do Estado do Rio de Janeiro. Acórdão em Agravo de Instrumento

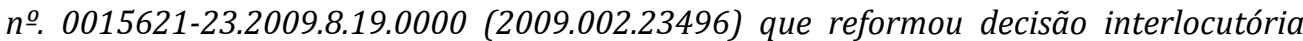
proferida em Medida Cautelar interposta por Município. Relator: Des. Monica Tolledo de Oliveira. Julgamento em 29.09.2009. Disponível em: <http://www4.tjrj.jus.br/ejud/ ConsultaProcesso.aspx?N=200900223496>. Acesso em 09 jun. 2016.

CARRAZZA, Roque Antonio. Curso de Direito Constitucional Tributário. 28. ed. São Paulo: Malheiros, 2012.

CARVAlHo FILHO, José dos Santos. Manual de Direito Administrativo. 23. ed. Rio de Janeiro: Lumen Juris, 2010.

DI PIETRO, Maria Zanella. Direito Administrativo. São Paulo: Atlas, 2010.

ESPÍRITO SANTO. Lei Complementar nº. 492 de 10 de agosto de 2009 e Portaria 029-S/10. Institui o Programa de Parcerias Público-Privadas do Estado do Espírito Santo e dá outras providências. Regimento Interno - Ver Decreto no 2410-R (D.0. de 27/1/09) e Portaria no 029-S (D.0. de 28/12/2010). Ver Decreto no 2889-R (D.0. de 03/11/11) que institui o Procedimento de Manifestação de Interesse para apresentação de projetos, estudos, levantamento ou investigações a serem utilizados em modelagens de projetos de Parcerias Público-Privadas, nas modalidades patrocinada e administrativa, e em projetos de concessão comum e permissão. Ver Decreto no 3072-R (D.0. de 09/08/2012) que institui o Programa de Gestão para Resultados do Governo do Estado do Espírito Santo realiza. In: Assembleia Legislativa do Estado do Espírito Santo, ES, 23 ago. 2009. Disponível em: <http://www.al.es.gov.br/novo_portal/>. Acesso em 10 abr. 2012.

GASPARINI, D. Direito Administrativo. São Paulo: Saraiva, 2005.

GONZALEZ, Andres Garcia. Parceria Público-Privada: Apontamentos Gerais. Disponível em: <http://www.advogado.adv.br/artigos/2005/andresgarciagonzalez/parceria.htm>. Acesso em 20 mai. 2016.

GOUVÊA, Marcus de Freitas. A extrafiscalidade no Direito Tributário e suas classificações. Revista Jus Navigandi, Teresina, ano 11, n. 1226, 9 nov. 2006. Disponível em: <https://jus. com.br/artigos/9151>. Jus Navigandi. Acesso em 07 jun. 2016. 
HARADA, Kiyoshi. Direito Financeiro e Tributário. São Paulo: Atlas, 2013.

LIMA, Jacqueline Baptista de Souza; PAULA, Luciane Maria Argenta de Mattes; PAULA, Rogério Carvalho. Entendendo a Parceria Público Privada no Brasil: Uma análise Preliminar. Revista Gestão Pública e Controle, v. 1, p. 79-111, 2007. Disponível em: <http:// www.unifra.br/pos/gestaoemturismo/downloads/PARCERIAS\%20PUBLIC0\%20 PRIVADAS.pdf $>$. Acesso em 09 jun. 2016.

MACHADO, Hugo de Brito. Curso de Direito Tributário. São Paulo: Malheiros, 2010.

MATO GROSSO. Lei no. 9.641 de 17 de novembro de 2011. Dispõe sobre o Programa Estadual de Parcerias Público-Privadas do Estado de Mato Grosso. In: Assembleia Legislativa do Estado de Mato Grosso, MT, 17 nov. 2011. Disponível em: <http://www.al.mt.gov.br/busca legislacao/?RestringeBusca=e\&Numero=9641>. Acesso em 10 abril 2012.

MEIRELLES, Hely Lopes. Direito Administrativo Brasileiro. São Paulo: Malheiros, 2009.

MINAS GERAIS. Decreto nํ. 43.702 de 16 de dezembro de 2003. Instala o Conselho Gestor de Parcerias Público Privadas - CGPPP e dá outras providências. In: Assembleia Legislativa do EstadodeMinasGerais, MG,16dez.2003.Disponível em:<http://www.almg.gov.br/consulte/ legislacao/completa/completa.html?tipo=DEC \&num $=43702 \&$ comp $=\& a n o=2003 \& a b a=j s$ textoAtualizado\#texto>. Acesso em 10 abril 2012.

PERNAMBUCO. Lei no. 12.765 de 2005. Dispõe sobre o Programa Estadual de Parceria Público-Privada, e dá outras providências. In: Assembleia Legislativa do Estado de Pernambuco, PE, 2005. Disponível em: <http://legis.alepe.pe.gov.br/pesquisaGeral. aspx?pagina $=0>$. Acesso em 10 abril 2012.

RIO GRANDE DO SUL. Lei nํ. 12.234 de 13 de janeiro de 2005. Dispõe sobre normas para licitação e contratação de parcerias público-privadas, institui o programa de Parcerias Público-Privadas do Estado do Rio Grande do Sul - PPP/RS - e dá outras providências. In: Assembleia Legislativa do Estado do Rio Grande do Sul, RS, 13 de jan. 2005. Disponível em: <http://www.al.rs.gov.br/legislativo/Legisla\%C3\%A7\%C3\%A3oEstadual.aspx>. Acesso em 10 abril 2012.

SABBAG, Eduardo. Manual de Direito Tributário. 1. ed.São Paulo: Saraiva, 2009. 